\title{
ACADEMIC RESEARCH PRACTICE: A GENUINE CAUSE OF CONCERN
}

\author{
SUKHDEV SINGH DHANJU \\ Ph.D. Scholar \\ Department of Sri Guru Granth Sahib Studies \\ Punjabi University, Patiala \\ Mob: 9530900533
}

\begin{abstract}
Exploration in research is directed to resolve the instructive issue and gives an answer that will animate viability inside the instructive area. Like different orders, instructive explores should be led without issues or bottlenecks that will frustrate the respectability of the examination or the scientists. This section distinguishes different issues that are at present rehearsed which are deceptive. The section likewise gives experiences into the angles that specialists and researchers should center to guarantee that dishonest issues are stayed away from when directing explores. Ends and suggestions were made to improve the ebb and flow rehearse towards worldwide prescribed procedures in the instructive exploration of the executives.
\end{abstract}

Keywords: Ethics, Domain, Conclusive, Potent, Empirical, Invention

\section{Introduction}

The object of examination is to broaden human information past what is now known. In any case, a person's information enters the area of science solely after it is introduced to others in such a style that they can freely pass judgment on its legitimacy. Examination gives the stage that researchers and researchers need to gather and convey the discoveries of their investigations, just as impart their thoughts. The reasoning behind the examination is information creation as well as progress. Subsequently, man's presence on earth was made conceivable through research as tested by God. It should be noticed that the whole cycle of creation was an examination try started by God on the grounds that even he (God), reasoned that everything produced using the test "was awesome" on the 6th day of creation prior to laying on the seventh day. By suggestion, research ends are constantly made dependent on the proof gave from investigations and examination of information. Given the significance of examination to humankind particularly as far as critical thinking and dynamic, certain guidelines and guidelines should be kept up and stayed away from to keep the cycle exuberant and streaming true to form. These guidelines and guidelines are known as moral issues in research, for the most part. Notwithstanding, investigates in training are not forgotten about without morals which should be followed. There are additionally manages, codes, guidelines, and conditions that should be continued in directing instructive exploration to stay away from issues and to support the uprightness of the examination results.

Instructive examination the board practice very much like different practices or trains necessitates that viability be guaranteed in each movement inside the cycle. This highlights the requirement for improved quality in instructive examination the board and practice. Frequently, numerous researchers take part in exploratory examinations with exact experimental outcomes to show from such examinations; be that as it may, in announcing such discoveries, a few issues are not given due thought. At the point when this is done, such a specialist has penetrated "moral codes," and the individual breaking such morals could confront genuine approvals and additionally liabilities whenever answered to fitting specialists. 
As indicated by the Center for Innovation in Research and Teaching (CIRT), moral contemplations in research are critical. Moral principles forestall the creation or distorting of information therefore, advance the quest for information and truth which is the essential objective of exploration. Moral conduct is likewise basic for community oriented work since it energizes a climate of trust, responsibility, and shared regard among specialists. This is particularly significant when considering issues identified with information sharing, co-origin, copyright rules, secrecy, and numerous different issues. Analysts should likewise hold fast to moral principles for the general population to help and have faith in the examination. The public needs to be guaranteed that analysts followed the proper rules for issues like common liberties, create government assistance, consistence with the law, irreconcilable circumstances, wellbeing, principles, etc. The treatment of these moral issues extraordinarily impacts the honesty of the examination project and can influence whether the task gets subsidizing (CIRT, 2019).

Exploration is a public trust that should be morally led, dependable, and socially mindful if the outcomes are to be important. All aspects of a research project - from the task plan to accommodation of the outcomes for peer audit - should be upstanding to be considered moral. When even one piece of an exploration project is sketchy or directed unscrupulously, the trustworthiness of the whole venture is raised doubt about (University of Minnesota Center for Bioethics (UMCB, 2003). Realizing what comprises moral examination is significant for all individuals who lead research ventures or utilize and apply the outcomes from research discoveries. All specialists ought to be comfortable with the fundamental moral standards and have exceptional information about arrangements and strategies intended to guarantee the wellbeing of exploration subjects and to forestall messy or flippant examination since obliviousness of approaches intended to secure examination subjects isn't viewed as a feasible pardon for morally problematic activities. Accordingly, the obligation lies with the analyst to search out and completely comprehend the arrangements and speculations intended to ensure upstanding exploration rehearses (UMCB, 2003).

Given the significance of morals for the lead of examination, it should not shock anyone that various expert affiliations, government organizations, and colleges have received explicit codes, rules, and approaches identifying with research morals. A wide range of controls, organizations, and callings have norms for conduct that suit their points and objectives. These principles additionally help individuals from the control to arrange their activities or exercises and to set up the public's trust in the order. For example, moral guidelines administer direct in medication, law, designing, and business. Moral standards additionally serve the points or objectives of instructive exploration the board and apply to individuals who practice/lead logical examination or other academic or imaginative exercises. There is even a particular order, research morals, which examines these standards (David and Resnik, 2015).

Having investigated the significance of morals in research, this part is worried about the introduction of what establishes moral issues in instructive exploration the executives and practice. These must consistently follow when leading instructive and other examination tests.

\section{Theoretical clarification}

\section{Principles}

Principles are the norms or standards for conduct that distinguish between right and wrong. They help to determine the difference between acceptable and unacceptable behaviors (CIRT, 2019). When we talk about ethics in general parlance, we are simply referring to those laws, rules, regulations, dos, and don'ts that are guiding a place, profession, or thing. In other words, these are simply those norms that must be adhered to. Ethics vary from place to place, culture to culture, profession to profession, and with time. 


\section{Research}

Research is a systematic and well-planned process of finding out the reality and truths underlying certain problems or phenomena of interest through observation and collection of data (using appropriate tools), analysis of data (using proper quantitative or qualitative techniques), presentation and interpretation of data, and through proper decision making (deductions or inference). The focus of educational research is to solve problems, create new knowledge and modify existing ones to suit the dynamics of society. Thus, for any exercise to be termed as research in education or elsewhere, it must be characterized by the ability to fore hidden truths that can be uncovered by mere intuition, it must also develop new techniques of doing things contextually, it must provide verifiable evidence to back the truth uncovered, and it must also be used to address issues that have raised the eyebrows of many people within an environment.

\section{Didactic Research Management}

Educational research management simply refers to the process of streamlining and tailoring research activities in education and its related disciplines towards realizing their goals. Every education research has broad and specific goals which they seek to attain. However, not all experiments in education achieve their intended objectives at the end for one reason or the other. Whatever the reason, any research that does not achieve pre-stated goals and objectives cannot be said to have been effectively managed. The aim of educational research management or simply research management is to remove all bottlenecks that may hinder the successful completion of any research endeavor in education. This can be achieved through proper planning, organization, budgeting, staffing, directing, coordination, and reporting.

Planning for any educational research activity is necessary to make a future forecast concerning what educational problem you intend to solve; why you intend to solve the problem identified; how you intend to solve the problem; when you intend to solve the problem; where you intend solving the problem; and who are those to benefit from such research. Taking these into consideration will give you an idea of the problem of the study/topic, location of the study, population/sample, methods of data collection/analysis, significance of the study, time/duration of the study, and so on. Organizing in educational research management implies that all the necessary information to conduct the study is properly harnessed and integrated. Such material that needs to be organized includes designing research instruments, sourcing for relevant literature that is related to the study, preparing citations, and referencing of other works used, including data collection, processing, presentation, and interpretation.

Budgeting is very crucial in every research endeavor because it sometimes predicts the scope of studies. It is appropriate to always consider how many resources you can provide to support the research. Budgeting is not only limited to available income, it also includes the willingness to set out resources to enable the conduct of a study, and the publication of research reports. Staffing as an educational research management process involves the appropriate selection of individuals required to collect from, or selection of research assistants to support in the data collection process.

Directing involves the process of passing instructions, guidelines, rules, and regulations to research participants, research assistants, and other members of the research team to enable them to understand their roles, what to avoid, and the care they must demonstrate to obtain reliable results. Coordination as a management function is very essential in educational research. It is very useful for studies involving collaboration because it enables all the members of the research team to work independently and yet collectively to achieve the sole aim of the 
research. Coordination simply means to ensure that all the sub-units or various individuals work in line with the objectives of the research.

The last aspect of the educational research management process is budgeting. Reporting entails that at the end of any educational research experiment, accurate documentation of the entire process including the aims, problem statement, hypothesis (for quantitative studies), methods, and results, be presented. The reason behind reporting research is to enable information sharing and problem-solving. This must also be done according to prescribe rules as may be determined by the publishers or institution. Another aspect of reporting in educational research management is the act of giving feedback to research grant providers on the extent to which the proposed research study has been carried out, including the strengths, weaknesses, opportunities, and threats facing the study.

\section{Moral Principles in Educational and Research}

As earlier stated, ethics are just rules which must be followed in acceptably doing a thing, or in a manner considered right. Therefore, ethics in educational research management are those ideals, rights, wrongs, and guidelines which scholars conducting educational researches are expected to follow to avoid problems in the research process and to produce research findings that may be used to address the educational concerns of the society. These ethics are not there to threaten researchers, but to serve as a blueprint guiding what should be done, and what shouldn't be done. It is, therefore, expedient that researchers acquaint themselves with ethical issues governing the conduct of research in education and beyond. This chapter thus provides such ethical issues and how they can be checked effectively.

\section{Ethical issues in educational research management and practice}

Ethical issues in educational research management and practice refer to those problems resulting from the breaching of prescribed ethics that ought to be followed when conducting educational research, or when managing the educational research process and activities. Below are some ethical issues in educational research management and practice.

\section{Copyright infringement issues}

Copyright means granting the exclusive right to research or other scholarly work for use, publication or sale. When documents are copyrighted, it means that such documents are protected under copyright laws are not meant to be used by anyone without prior permission from the author, creator or copyright owner. The use of such protected works by copyright laws constitutes what is known as copyright infringement. Therefore, copyright infringement simply refers to a situation where individuals make use of copyrighted files for personal or commercial purposes without receiving prior access from the copyright owners. It is a serious offense that is punishable by law.

However, in educational research management or practice, it is common to see many students, lecturers, researchers, and scholars make use of other peoples' work that is copyrighted without gaining prior consent from the authors or copyright owners of such work. It does not even matter whether only a small part of such protected files has been used. Copyright policies apply to both copying in parts or whole. To avoid this, it is very important to identify copyrighted documents either online and/or offline, then gain proper access from those concerned, before using them as instructed. 


\section{Fabrication issues}

American Speech-Language-Hearing Association (ASHA) (2018, p3.), defines fabrication as "making up data or results and recording or reporting them." Examples of fabricating research data or results and recording or reporting them include creating spreadsheets that contain demographic information and performance results for research participants who do not exist and creating figures for the public presentation that contain results of physical measures of sound outputs for auditory devices that cannot produce these levels.

It is common to find many researchers and scholars who fabricate in educational research. Areas where fabrication usually occurs include data collection/generation, citations, literature review, and data analysis. Many researchers do not go to the field to collect data, they stay indoors and generate (cook) data that are not true. In terms of citations, it is also common to see researchers cite authors who did not make such statements, just because of the inability to get the real author of the work. In the literature review, many scholars have been observed developing empirical studies that do not exist. They do this most often to provide a base in the literature review of their studies to aid in the discussion of their results. This is usually done by highly experienced researchers who design empirical studies that do not exist and make them look so real.

\section{Falsification issues}

Falsification issues simply refer to a situation where researchers intentionally manipulate people's ideas, research data, and citations to suit the context of their studies. ORI (Office of Research Integrity) defines prevarication as "manipulating research materials, equipment, or processes, or changing or omitting data or results such that the research is not accurately represented in the research record." Examples of falsifying research data and/or reporting such data include:

Reporting data that were not collected

Altering data collected to achieve a particular outcome

Reporting only data that support your hypotheses and/or interests, and

Making false claims in promotional materials about what one's research has demonstrated or supported.

Many scholars in the course of writing, may change the dates in old studies by putting in new dates to make the work appear current. Some researchers also manipulate research data by constantly modifying data and tuning them to the direction that suits their intentions and positions. It is also common to see many researchers who deliberately add their own comments and ideas (even after appropriate citation) to other peoples' ideas in other to make such ideas support their point of view. Changing the location of a study to make it look different or modifying another person's research topic in parts or in full while retaining the person's work in parts or full as your own is a falsification. All these, and many more, are unethical in educational research and should be avoided for effective problem-solving.

\section{Plagiarism}

Literary theft is the demonstration of passing off another person's thoughts, considerations, pictures, speculations, words, or stories as your own, characterizes counterfeiting as "the allocation of someone else's thoughts, cycles, results, or words without giving suitable credit." Representing any part or parts of another's work as one's own is viewed as copyright 
infringement. Literary theft takes numerous structures. Toward one side of the range are individuals who purposefully take a section in the same words, put it in their work, and don't as expected credit the first creator. The opposite end comprises of unexpected (or apathetic) reworded and divided writings the writer has sorted out from a few works without appropriately referring to the sources.

There are numerous regions where analysts are obligated to submit literary theft purposefully or inadvertently. Leading a survey of the writing that neglects to recognize the commitments of others in the field or applicable earlier work (David and Resnik, 2015) is counterfeiting. Utilizing information, figures, or diagrams from other people groups' work without recognizing additionally establishes counterfeiting. Copyright infringement goes from unreferenced utilization of others distributed and unpublished thoughts, including research award applications to accommodation under "new" creation of a total paper, now and then in an alternate language.

As indicated by acts in research comprise literary theft. Neglecting to perceive understudies or some other benefactors as creators of exploration or insightful work or appointing initiation credit to a person who has not added to investigate or academic work, may bring about an infringement of examination standards. Utilizing direct statements or summarizing distributed exploration to propose that the author(s) of the examination supported an item, treatment, the item is literary theft and may abuse research standards and rules. Consequently, it is essential to uncover all wellsprings of data, and if a lot of others' composed or illustrative materials are to be utilized, consent should be looked for (Jenn, 2006).

To keep away from copyright infringement, it is likewise appropriate to refer to all thoughts, information, and data that are of others and not your insight/thoughts; consistently use quotes if you are utilizing another person's thoughts that are under 40 words, or indent such long citations that are over 40 words to show they are not your words or thoughts; toward the start of a reworded area, show that what comes next is another person's unique thought (for instance, as per John) and toward the finish of a summarized segment, place the legitimate reference. On the side of fitting practices expected of scientists, "people will reference the source when utilizing other people's thoughts, research, introductions, results, or items in composed, oral, or some other media show or synopsis. To do in any case establishes counterfeiting".

\section{Citations issues}

Citations and referencing issues are related to issue of falsification and plagiarism. Citation is simply a process where authors give credit to the appropriate source from where a piece of information used in the work that is not theirs, was collected. A lot of facts ranging from ideas, quotations, data, figures, tables, comments, findings, and many more can be cited to explain, present, or clarify an idea, or to provide evidence and/or justification to a point the scholar is trying to make.

Referring to, then again, is basically a rundown showing every one of the different creators/sources that were referred to in the body of the work. The point is to give subtleties of the sources from where data has had the opportunity to empower different researchers to check or find such sources as their own requirements may interest. Reference and referring to are interlaced on the grounds that referred to works are relied upon to all show up in the referring to the rundown, and every one of the creators or sources found in the referring to rundown will be accepted to have been referred to in the principle work. In standard examination practice, numerous students, postgraduates, and even researchers don't appear to know about this connection among the reference and referring to. Thusly, it is feasible to get many examinations contemplates and find works that have been referred to in the rundown, that were 
not referred to in the fundamental work; or that references have been made without posting them in the references.

\section{Publication Issues}

Publication issues refer to those unethical practices that occur during the publication of scholarly works, and which must be avoided to guarantee effective educational research management and practices. Such issues include: submitting the same paper to different journals without telling the editors; publishing the same paper in two different journals without telling the editors; bypassing the peer review process and announcing your results through a press conference without giving peers adequate information to review your work; publishing research works without proper peer review.

Other unethical issues about publication include: collecting monies from authors without publishing their works; announcing the publication of a work in a different month/volume/issue from when it was supposed to be published; charging authors for vetting fees without any review of their manuscript; have your papers reviewed in open access journals and sending same to another Journal for publication; publishing works online or in print without sending hard copies or publishing them online after charging publication fees for both online and print; and many others are issues usually faced in the process of publication.

For effective management of educational research, all these issues highlighted above must be strictly avoided including the issue of redundant publication. According to Giles (2005), redundant publication occurs when two or more papers, without full cross-reference, share the same hypothesis, data, discussion points, or conclusions. However, previous publication of an abstract during the proceedings of meetings does not preclude subsequent submission for publication, but full disclosure should be made at the time of submission. This is also known as self-plagiarism. In the increasingly competitive environment where appointments, promotions, and grant applications are strongly influenced by publication records, researchers are under intense pressure to publish, and a growing minority is seeking to bump up their CVs through dishonest means.

\section{Authorship Issues}

Origin is the way toward shortlisting people whose names ought to show up as engineers, makers, and proprietors of exploration work. Origin like numerous different terms has no general definition because of varieties in the conclusions and mentality of researchers. In any case, it is by and large concurred that a creator ought to have made a considerable commitment to the scholarly substance, including conceptualizing and planning the examination; gaining, breaking down, and deciphering the information (Jenn, 2006). For somebody or individuals to be alluded to as creators, they need to show that their work is unique, substantial, and has not been distributed somewhere else by possibly them or some other gathering. A creator should likewise be engaged with drafting or amending the original copy, just as supporting the submitted composition for distribution. The individuals who aided the assortment of information, confirming, and typesetting of insightful works don't have the right to be incorporated as creators. Nonetheless, their endeavors might be recognized. As per Jenn (2006), it is urgent to choose right off the bat in the arranging of examination who will be credited as creators, as donors, and who will be recognized. It is additionally prudent to peruse cautiously the "Exhortation to Authors" of the objective diary which may fill in as a manual for the issue of initiation.

Some deceptive issues in origin that are typical in the instructive examination include: not advising an associate regarding your expectation to record a patent to ensure that you are the sole creator; remembering a partner as a creator for a paper as a trade-off for some help even 
though the partner didn't make a genuine commitment to the paper; procurement of financing, the assortment of information, or general management of the exploration bunch, without anyone else, don't legitimize initiation. Others include: battling to lead a paper in an examination work since you are higher in power in any event, when your endeavors are not when contrasted with other people who are lower in positions. Driving a paper summed up from an understudy's work as an instructor; changing the request in the rundown of writers during distribution without telling others; eliminating the names of different writers without telling during distribution correspondence; paying monies for distribution of articles just with no critical commitment in the advancement of the exploration work doesn't likewise qualify one for creation.

In light of the prior, it is important to notice and avoid every one of these dishonest practices about initiation and guaranteeing that solitary worthy behaviors are rehearsed. UMCB (2003) cautioned that every one of the contributing co-writers of an article should together choose the request for the posting of names. The main individual recorded ought to be the individual most firmly engaged with the exploration. The creators should then choose the request for the excess creators under the rules of the distributing diary and be set up to address inquiries regarding why the request is as it shows up.

\section{Privacy Issues}

Confidentiality issues arise when information that ought to be concealed is revealed to the public through any means. During the research process, certain personal and identifiable information of research participants, authors, and reviewers need not be exposed for any reason. This is to offer protection to the subjects and ensure that they are free in providing the desired information sought after. During peer review, it is also important for the editor to remove all personal and identifiable data of authors from manuscripts before sending them to for review. Details about who is reviewing a paper should not also be disclosed to authors.

Individuals taking an interest in research are qualified for secrecy regardless of whether the aftereffects of the exploration are unveiled. Data ought not to be uncovered to anybody outside the examination group except if earlier approval has been acquired. Much of the time, namelessness is ensured, and members might be allowed code names or numbers. This empowers the specialists to cite individuals without uncovering their personalities (AlzheimerEurope, 2009). Also, any close-to-home/private data that analysts learn of over the span of the examination, which isn't identified with the investigation, ought not to be unveiled to anybody. Examining with your associates, classified information from a paper that you are investigating for a diary. Sharing data that can be utilized to recognize an exploration member is an infringement of examination morals.

In any event, uncovering insignificant data e.g., initials of member's name, jumble,

address of the member, parts of treatment) through any type of correspondence, including online media, may permit others to recognize the member and might be an infringement of examination standards. No additional individual information ought to be accumulated that isn't promptly relevant to the investigation. The individual information will be painstakingly coordinated and figured out how to guarantee that no unapproved use is made of them.

Analysts ought to likewise mull over how they will guarantee the protection and secrecy of the members. It is sensible for anybody participating in an examination to expect a specific degree of namelessness, albeit a few members may not feel this is an over-the-top worry for them (particularly among the more youthful age of 'public face online media clients). Regardless of whether personalities will be uncovered and how pictures and other recognizing components may be utilized should be painstakingly haggled with the subjects of the investigation. Subjects 
in an examination reserve an option to think enough about the investigation to choose whether they need to partake in the investigation. On account of minors, parental consent (frequently through the schools) ought to be acquired. Ensure private correspondences, for example, papers or awards submitted for distribution, workforce records, exchange or military privileged insights, and patient records.

In certain investigations, especially limited scope subjective examinations or activity research, specialists may choose to show the fundamental outcomes to the members and welcome them to remark. This permits them to affirm or question whatever has been expounded on them just as to be all the more completely associated with the examination. This is vital in examinations that have included individual contact or with members who have shared individual data about themselves.

\section{Data Analysis Issues}

According to Jenn it is the responsibility of the researcher to analyze the data appropriately. Although the inappropriate analysis does not necessarily amount to misconduct, intentional omission of the result may cause misinterpretation and mislead the readers. Fabrication and falsification of data do constitute misconduct. For example, in educational research which assesses the performance of male and female students, a male analyst can increase the scores of male students just to ensure that he reaches the conclusion that; males are more brilliant than females. Issues like this are misleading because they provide erroneous results. There is a tendency for the researchers to under-report negative research findings (Smith, 2005), and this is partly contributed by pressure (Jenn, 2006). Trimming outliers from a data set without discussing your reasons in paper and using an inappropriate statistical technique to enhance the significance of your research (David \& Resnik, 2015) are other issues involved in data analysis.

Against all these issues, Dooly et al. (2017) advised that researchers should also try to be as ethical as possible when interpreting the study results. Researchers should do their best to not over-interpret or misinterpret the data and represent the possible conclusions as closely as possible. To do so, researchers can use triangulation techniques or corroborate their conclusions with the participants themselves through interviews and other techniques proposed in qualitative methodologies (Dooly, et al., 2017). To ensure appropriate data analysis, all sources and methods used to obtain and analyze data should be fully disclosed. Failure to do so may lead the readers to misinterpret the results without considering the possibility of the study being underpowered. The discussion section of a paper should mention any issues of bias and explain how they have been dealt with in the design and interpretation of the study.

\section{Research Management Issues}

Supervision of research staff, collaborators, and students is an integral part of scholarly activity and research (ASHA, 2018). All individuals involved in research must be held to the highest levels of ethical conduct. Supervisors must ensure that all individuals involved in the research project receive appropriate training and are competent to conduct assigned research activities.

Common issues in research supervision which must be avoided include: giving the same research project to two graduate students to see who can do it the fastest; overworking, neglecting, or exploiting graduate or post-doctoral students and promising a student a better grade for sexual favors (David \& Resnik, 2015); publishing a supervisee work as your own; forcing students to pay for data analysis against their interest; delaying students' work unnecessarily for selfish reasons; assessing students' works only after financial, sexual or other dubious obligations have been met; and so on. Thus, the research supervisor should maintain professional supervisor-supervisee relationships and assign credit appropriately, and failure of 
individuals in supervisory or administrative roles to delegate research responsibilities appropriately to students or staff may result in violation of research principles (ASHA, 2018).

\section{Peer Review Issues}

Peer review is the process in which an author (or authors) submits a written manuscript or article to a journal for publication and the journal editor distributes the article to experts working in the same, or similar, scientific discipline. The experts are otherwise called the reviewers, and the editor then enters the peer review process. The entire process may involve several rounds of communication between the editor, the reviewers, and the original author (or authors) before an article is fully ready for publication. The two most important ethical concepts in the peer review process are confidentiality and the protection of intellectual property. Reviewers should not know the author (or authors) they are reviewing, and the author (or authors) should not be told the names of the reviewers. Only by maintaining strict confidentiality guidelines can the peer review process be truly open and beneficial. Likewise, no person involved in the peer review process - either the editor, reviewers, or other journal staff - can publicly disclose the information in the article or use the information in a submitted article for personal gain (UMCB, 2003).

Peer reviewers, in addition to maintaining confidentiality, can be neither conflicted nor political in their review. Conflicts may take the form of financial conflicts with the results, conflicts if the research is too similar to their research endeavors, and conflicts due to personal relationships with the author (or authors). Political motivations that might interfere with the peer review process include a competition to publish with other scientists and inaccurate reviews designed to "punish” a competing colleague or Journal.

Editors may find it difficult to guarantee a conflict-free peer-review process because reviewers must be experts with knowledge unique to the field to which the article pertains. Therefore, many reviewers may find themselves faced with an article concerning research that is very similar to their own. Peer reviewers should disclose all conflicts of interest that may unduly influence their review to the journal editor and disqualify themselves when appropriate (UMCB, 2003).

Editors of Journals should maintain an open and ethical peer review policy, and all submitting authors and readers should be fully aware of a journal's process of peer review. Editors do retain flexibility in assigning the number of peer reviewers and what to do with the peer review information once completed. One method is for an editor to approach two or three reviewers and then ask an author (or authors) to change the article to satisfy all the reviews. On the other hand, an editor may take all the reviews and consolidate the advice to help guide the author (or authors) when making changes, clarifications, and corrections (UMCB, 2003). Editors must not relinquish too many of their responsibilities to peer reviewers. The peer-review process represents one step in the publishing process and editors need to take full responsibility for their decision to include an article in their journal. This means that editors must review the content and character of a submitted article, using all the criteria listed for reviewers above, and should rely on the reviewers primarily to catch errors that lie outside the editor's area of expertise and technical understanding (Lawrence, 2003).

\section{Discrimination issues}

A foundational principle of research is the inclusion of the varied demographics of the population under study. An additional foundational principle is a fundamental respect for individual differences by those who design, execute, and report research. Discrimination in the selection and treatment of human participants may be the result of explicit or implicit bias. One example would be excluding a specific group (e.g., individuals who identify as bisexual) 
because of personal bias when that variable (sexual orientation) would not influence the research study's outcome. Therefore, it is necessary to avoid discrimination against colleagues or students based on sex, race, ethnicity, or other factors not related to scientific competence and integrity.

\section{Conflicts of Interest}

This happens when researchers have interests that are not fully apparent and that may influence their judgments on what is published. These conflicts include personal, commercial, political, academic, or financial interests. Financial interests may include employment, research funding, stock or share ownership, payment for lecture or travel, consultancies, and company support for staff. This issue is especially pertinent in biomedical research where a substantial number of clinical trials are funded by a pharmaceutical company (Jenn, 2006; ASHA, 2018). Even if a researcher is offered, or receives, gifts or incentives - even something as minor as a free lunch there may be a conflict of interest.

Such interests, where relevant, should be discussed in the early stage of research. The researchers need to take extra effort to ensure that their conflicts of interest do not influence the methodology and outcome of the research. It would be useful to consult an independent researcher, or Ethics Committee, on this issue if in doubt. When publishing, these conflicts of interest should be declared to editors, and readers will judge for themselves whether the research findings are trustworthy.

\section{Fund Issues}

Grants are financial supports offered to researchers and scholars who have identified a unique problem and have mapped strategies in solving the problems, to enable them to conduct such investigations without challenges. Grants are provided without interest nor return by organizations and individuals. For instance, a researcher may want to address the issues of security challenges in Northern Nigeria without having adequate funds to produce research instruments that will serve all the states in the north or travel from place to place to collect data and to publish the research findings in reputable Journals. Thus, interested organizations may support by providing funds that will ensure the smooth conduct of such a study.

However, ethical issues concerning research grants have also emerged. These issues range from grants allocation to grants utilization. It is unfair to give grants to people because of their ties with an organization even when the problem they intend to address is not as pressing as those of other competing grants seekers. For social, economic, political, and religious reasons, grants are usually given to unproductive researches against the novel ones. On the other hand, most researchers and scholars do not make use of research grants for the execution of the actual research. Some see it as an opportunity to alleviate poverty by spending such funds in solving household problems without conducting the proposed study. In other cases, researchers intentionally use part of the grants for other private investments, while only channeling an insufficient part of the grant to the actual study. Consequently, the research is not conducted as supposed, leading to fabrication and falsification of data and other truths. Issues related to research grants can be avoided through honesty in the allocation of grants, and in the utilization of grants.

\section{Conclusion}

Education research cannot be successfully conducted without paying attention to the ethical issues bordering on it. In time past, several scholars have made one mistake or the other intentionally, due to ignorance or through lack of awareness. Numerous ethics must be 
followed for effective educational research management and practice. These have been explained exhaustively, the onus is now on students, researchers, and scholars to abide by such ethics for improved problem solving and effective decision making in researches conducted in education and beyond.

\section{References}

AlKahtani, S. (1999). Teaching ESL reading using computers. The Internet TESL Journal, 5(11). Retrieved from http://iteslj.org/Techniques/AlKahtaniComputerReading/

Constantinescu, A. I. (2007). Using technology to assist in vocabulary acquisition and reading comprehension. The Internet TESL Journal, 13(2). Retrieved from http://iteslj.org/Articles/Constantinescu-Vocabulary.html

Davies, G., \& Hewer, S. (2012). Introduction to new technologies and how they can contribute to language learning and teaching. Module 1.1 in Davies G. (ed.), Information and Communications Technology for Language Teachers (ICT4LT), Slough, Thames Valley University [Online]. Retrieved from http://www.ict4lt.org/en/en mod1-1.htm

Hoven, D. (1999). A model for listening and viewing comprehension in multimedia environments. Language Learning \& Technology, 3(1), 88-103. Retrieved from http://lt.msu.edu/vol3num1/hoven/index.html

Kenworthy, R. C. (2004). The Internet TESL Journal, Developing writing skills in a foreign language via the internet.10(10). Retrieved from http://iteslj.org/Techniques/Kenworth-WritingSkills.html

Saricoban, A. (1999). The teaching of listening. The Internet TESL Journal, 5(12). Retrieved from http://iteslj.org/Articles/

Saricoban-Listening.html Seedhouse, P. (1994). Using newspapers on CD-ROM as a resource. TESL-EJ, 1(2). Retrieved from http://www.teslej.org/wordpress/issues/volume1/ej02/ej02a3/

Sharma, P. (2009, April 8). Controversies in using technology in language teaching. Retrieved from http://www.teachingenglish.org.uk/articles/controversies-

The internet and foreign language education: Benefits and challenges. The Internet TESL Journal, 3(6). Retrieved from http://iteslj.org/Articles/Singhal-Internet.html

Ybarra, R., \& Green T. (2003). Using technology to help ESL/EFL students develop language skills. The Internet TESL Journal, 9(3). Retrieved from http://iteslj.org/Articles/Ybarra-Technology.html 